\title{
Retinoblastoma epidemiology: Does the evidence matter?
}

\author{
D. Mastrangelo ${ }^{a, *}$, S. De Francesco ${ }^{a}$, A. Di Leonardo ${ }^{b}$, L. Lentini ${ }^{b}$, T. Hadjistilianou ${ }^{a}$

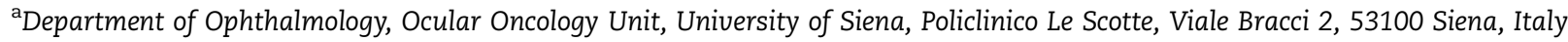 \\ bDepartment of Cell and Developmental Biology 'A. Monroy', Palermo, Italy
}

\section{A R T I C L E I N F O}

\section{Article history:}

Received 18 January 2007

Received in revised form 17 March

2007

Accepted 19 April 2007

Available online 31 May 2007

Keywords:

Retinoblastoma

Aneuploidy

Two hit theory

Microsatellite instability

Chromosome instability

Epigenetic

\begin{abstract}
A B S T R A C T
It has been proposed that retinoblastoma is 'caused' by two sequential mutations affecting the RB1 gene, but this is a rather outdated view of cancer aetiology that does not take into account a large amount of new acquisitions such as chromosomal and epigenetic alterations.

Retinoblastoma remains probably the only cancer in which the rather simplistic 'two hit' mutational model is still considered of value, although cancer is known to be associated with genomic and microsatellite instability, defects of the DNA mismatch repair system, alterations of DNA methylation and hystone acethylation/deacethylation, and aneuploidy.

Moreover, as it is shown herein, the predictions made by the 'two hit' model, are not fulfilled by the clinical and epidemiological data reported so far. Moreover, while the role of mutational events in cancer has been largely questioned in the more recent literature, no serious effort has been done to investigate the role of epigenetic alterations and aneuploidy in retinoblastoma.

Through the analysis of the specialised literature and a set of original epidemiological and biological data concerning retinoblastoma, the authors illustrate the evidences arguing against the 'two hit' hypothesis and propose that epigenetic factors and aneuploidy play central roles in the disease.
\end{abstract}

(C) 2007 Elsevier Ltd. All rights reserved.

\section{Introduction}

Retinoblastoma $(\mathrm{Rb})$ is a tumour affecting the retina of one (unilateral $\mathrm{Rb}$ ) or both eyes (bilateral $\mathrm{Rb}$ ) in children. Enucleation (i.e. the surgical ablation of the affected eye), with consequent blindness, still represents a common modality in the management of the disease, even if more 'conservative' approaches have become increasingly practiced in recent years, thanks to the availability of newer and more sophisticated local treatment modalities. ${ }^{1}$

A large amount of highly specialised information on retinoblastoma is presently available through the Internet and at easy reach by anyone wanting to get detailed information on this eye tumour affecting young children.
However, the honourable purpose of spreading information that can be invaluable for affected patients and their parents, should not lead to disregarding the absolute necessity of a strict control on the quality and reliability of the information itself, particularly when the 'audience' is as large as that of the worldwide web users.

A closer look at the information reported on retinoblastoma by some groups of qualified scientists in this field, gives us the opportunity to discuss some of the statements, concepts and ideas regarding this disease that, to our opinion, are far from being definitively demonstrated and accepted.

One example is represented by the definition of the role of the RB1 gene in retinoblastoma. As reported in one of

* Corresponding author: Tel.: +39 577 369101; fax: +39 577369185.

E-mail address: mastrangelo@unisi.it (D. Mastrangelo). 
the most recent and complete Internet reports on this disease '...Retinoblastoma occurs in cells that have a predisposing mutation of the RB1 gene' and also: '...RB1 is the only gene known to be associated with retinoblastoma', and finally: 'Hereditary retinoblastoma, caused by germline (RB1) mutations, is inherited in an autosomal dominant manner'. ${ }^{2}$ Although both the web and the current literature seem to confirm these different views concerning the role of the RB1 gene in retinoblastoma, ${ }^{3-5}$ it is not difficult to see that 'association', 'predisposition', and 'causation' are not one and the same concept and that they cannot all be attributed to the RB1 gene without generating a certain amount of confusion.

What 'predisposes' to cancer or any other disease cannot possibly be viewed as a 'cause' in itself, but rather as a favouring condition or co-factor. On the other hand, the 'association' of a certain feature (such as a gene mutation) with a given disease, is not necessarily a proof of its role as a 'causative' or 'predisposing' factor, unless the association is $100 \%$ sensitive (all affected patients have the mutation), 100\% specific (all non affected patients do not have the mutation), 100\% accurate (no false positive and false negative cases), and clinically and biologically sound (evidence must show a close and logical relationship between the feature associated to the disease and the disease itself).

Regarding the RB1 gene mutations, the following must be outlined about their 'association' with retinoblastoma:

1. They have been reported to vary from $10-20 \%$ in some reports ${ }^{6}$ to around $89 \%$ in others, ${ }^{7}$ using experimental procedures and selection criteria biased toward the inclusion of a large excess of bilateral cases. ${ }^{7,8}$ Globally, RB1 gene mutations can be found in no more than $50 \%$ (low sensitivity) of all cases, according to some of the most recent reports ${ }^{9}$;

2. they are commonly found in a great number of non retinoblastoma cancers ${ }^{9,10}$ such as osteosarcoma, breast, bladder, lung, head and neck cancer, acute leukaemia, etc. (poor specificity);

3. as a consequence, they are neither accurate nor clinically and biologically sound or relevant with respect to their possible role in the genesis of retinoblastoma;

4. they do not represent the only characteristic feature of the disease in 'positive' cases if we consider that:

(a) Other genes, such as Rb2 may be non expressed in retinoblastoma; ${ }^{11}$

(b) Non structural alterations of the expression of genes such as RASSF1A, caspase 8 and 10, HIC1, HIN-1, which have a defined role in paediatric cancer, can be found in at least $50 \%$ of retinoblastoma investigated. ${ }^{12-15}$

Taken together, the above facts alone would have been more than a convincing evidence, for the average unbiased scientist, to cast at least some doubts about the role of the RB1 gene in retinoblastoma; not so for the retinoblastoma 'establishment' and experts, who, in spite of all this, still persist in attributing to the RB1, the roles of 'predisposing', 'associated', and 'causing' factor, ${ }^{2}$ as if they were one and the same thing, thus perpetuating, since more than three decades, a great deal of confusion and uncertainty about this important matter.

But other and more relevant aspects of the theory behind the genesis of retinoblastoma (The 'two hit' theory), ${ }^{16}$ particularly those regarding the causative and predisposing role of the RB1 gene in retinoblastoma, strongly deserve to be reviewed in the light of clinical and epidemiological evidences, as it is shown herein.

\section{Materials and methods}

Clinical records of 387 patients referred to the Department of Ophthalmology (Ocular Oncology Unit) of the University of Siena, have been selected and analysed for the present investigation, with emphasis on data such as laterality (unilateral and bilateral disease), distribution of the age at diagnosis, family history, and distribution of the clinical phenotype (unilateral/bilateral) within the 'genetic' groups ('familial', 'hereditary', 'sporadic' retinoblastoma) of the disease.

A literature search of the same data was also performed in order to increase the statistical consistence and compare the clinical evidences with the corresponding predictions made by the 'two hit' theory.

Original data concerning the role and significance of aneuploidy in retinoblastoma were supplied by two of the authors and reported in detail in the 'discussion' section of this paper.

\section{Results}

The central assumption of the 'two hit' hypothesis, formulated by Knudson in $1971^{16}$ is that, being retinoblastoma, dependent on two sequential mutations affecting one and the same gene (RB1), the variegated phenotypic expression of the disease (i.e.: unilateral, bilateral, 'trilateral' retinoblastoma, retinoma, etc.) must be related to the different timing between the first and the second 'hit' (i.e.: mutation). Knudson realised that his theory predicted differences in the patterns of age-specific incidence between inherited and sporadic retinoblastoma, and since the appearance of his first article on this subject, agreement was reached, among clinicians and epidemiologists, on the fact that: '.. About $60 \%$ of affected individuals have unilateral $\mathrm{RB}$ with a mean age of diagnosis of 24 months; about $40 \%$ have bilateral RB with a mean age of diagnosis of 15 months...'2 The $60 \%$ referred to in the above sentence is represented by the unilaterally affected patients in which both 'hits' involve the somatic cells (retinoblasts); while the remaining $40 \%$ is represented by the bilaterally affected patients in which the first 'hit' is inherited through the germ cells from either affected (familial retinoblastoma) or unaffected ('new germline' retinoblastoma) parents.

The theory illustrating the relationship between the timing and the target of the first and second 'hit', on one side, and the age distribution of retinoblastoma, as related to its inherited or sporadic nature, on the other, has been further detailed and explained in a number of publications by the same author, ${ }^{17-34}$ and is presently a consolidated and accepted view among scientists worldwide. 
Fig. 1 shows the 'theoretical' distribution of the age at diagnosis as predicted by the 'two hit' model proposed by Knudson. Since the model predicts that the mean age at diagnosis for bilateral and unilateral cases is 15 and 24 months, respectively, a 'normal' (bell shaped) distribution will show two different curves, whose size and width may vary, depending on the sample size and the spreading of values, but substantially similar to those reported in Fig. 1.

As a matter of fact, the clinical evidence shows us a quite different situation. On a sample of 387 patients referred to the Department of Ophthalmology of the University of Siena, we have found the distribution reported in Fig. 2. As it is shown in the figure, while bilateral retinoblastoma disappears after the age of 36 months, unilateral retinoblastoma spreads over a much wider range, with twelve cases having an age at diagnosis of over 100 months (not reported in the diagram), the latest of which had been diagnosed at the ages of 204, 481, and 540 months $(17,40$, and 45 years) respectively. This is a quite typical distribution of the age at diagnosis for both unilateral and bilateral retinoblastoma on a representative sample.
To further reinforce this view, we have selected from the literature, series in which retinoblastoma patients were allocated in groups according to the age at diagnosis, ${ }^{35-38}$ and found that, on a total of 1160 retinoblastoma patients, $86 \%$ of bilateral and $76 \%$ of unilateral retinoblastoma had been diagnosed within the first 24 months of life (Table 1).

Moreover, since, according to the theory, the inheritance of the first mutation through the germ cells leads to the development of the bilateral phenotype in the vast majority of cases (more than 90\%), it follows that familial retinoblastoma with unilateral disease should be exceedingly rare, i.e. much less than the predicted $10 \%$ within the hereditary (familial + new germline) group of retinoblastoma.

Table 2 shows that, on a group of 3581 retinoblastoma, there is a total number of 343 (9.5\%) familial cases. Within this group, 84 patients developed unilateral retinoblastoma, a figure which represents the $23 \%$ of all familial cases.

Finally, the 'two hit' model assumes that every bilaterally affected individual carries a germline mutation even in the absence of a family history, thus behaving as an 'initiator' or 'founder', in terms of transmission of the disease. To verify

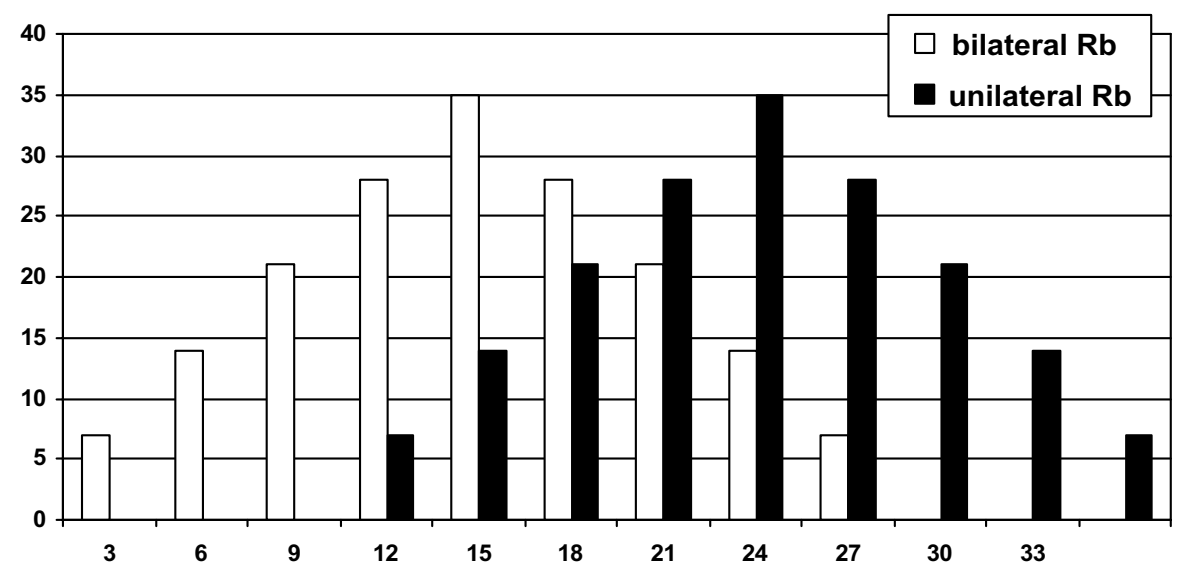

Fig. 1 - The normal (hypothetical) distribution of the age at diagnosis is represented for both unilateral and bilateral retinoblastoma, with a mean age of 15 months for bilateral and 24 months for unilateral disease. According to the current interpretation, unilateral retinoblastoma is 'globally' diagnosed later than the bilateral one. This distribution, however, does not represent the clinical reality.

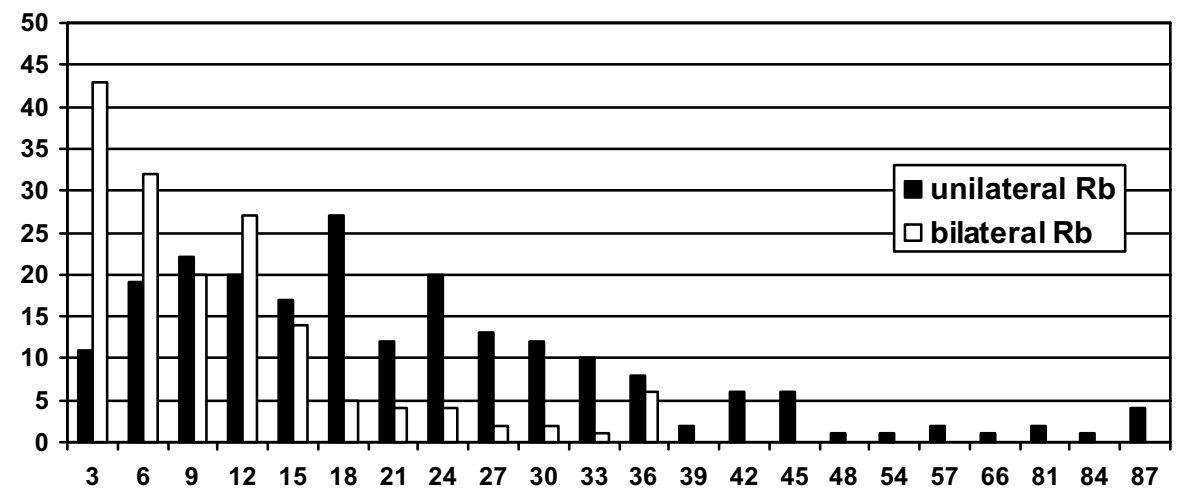

Fig. 2 - The age distribution curve of unilateral and bilateral retinoblastoma on a sample of 387 cases. The sample encompasses $227(59.7 \%)$ unilateral and 160 (41.3\%) bilateral cases. 12 unilateral cases are not reported in the diagram since their ages at diagnosis were over 100 months. 
Table 1 - Bilateral retinoblastoma diagnosed on or before the age of 2 years (24 months) (by the age of 24 months, $306 / 377$ (81\%) bilateral and 553/729 (76\%) unilateral retinoblastoma have already been diagnosed)

\begin{tabular}{|c|c|c|c|c|c|c|c|}
\hline & URb & $\mathrm{BRb}$ & Tot. & $u \leqslant 1 y$ & $b \leqslant 1 y$ & $u \leqslant 2 y$ & $b \leqslant 2 y$ \\
\hline Pendergrass (a) & 54 & 14 & 68 & 23 & 13 & 38 & 14 \\
\hline Tamboli (b) & 166 & 54 & 220 & 93 & 48 & 125 & 53 \\
\hline Sanders (c) & 282 & 149 & 431 & 55 & 91 & 249 & 123 \\
\hline Hadjistilianou (d) & 227 & 160 & 387 & 72 & 121 & 146 & 148 \\
\hline Tot. & 729 & 377 & 1106 & 233 & 225 & 553 & 306 \\
\hline
\end{tabular}

$\mathrm{URb}=$ Unilateral retinoblastoma; $\mathrm{BRb}=$ Bilateral retinoblastoma; $u \leqslant 1 y=$ Unilateral retinoblastoma diagnosed on or before the age of 1 year (12 months); $b \leqslant 1 y=$ Bilateral retinoblastoma diagnosed on or before the age of 1 year (12 months); $u \leqslant 2 y=$ Unilateral retinoblastoma diagnosed on or before the age of 2 years (24 months).

(a) Arch. Ophthalmol., 1980, (b) Arch. Ophthalmol., 1990, (c) Br. J. Ophthalmol, 1988, (d) Eur. J. Cancer, 2007.

Table 2 - On a total of 3581 retinoblastoma, 344 (9.5\%) have a positive family history for the disease (within this group, the incidence of unilateral cases is $23 \%$, while, according to the predictions made by the 'two hit theory', this percentage should be equal to or lower than that found in the general retinoblastoma population (i.e.: 6-6.5\%))

\begin{tabular}{lrrrrrr} 
Author & URb & BRb & Tot. & Fam.U & Fam.B & Tot. Fam \\
\hline Abramson (a) & 626 & 905 & 1531 & 36 & 10 & 150 \\
Gunalp (b) & 441 & 195 & 636 & 15 & 24 & 34 \\
Sanders (c) & 282 & 149 & 431 & 11 & 38 & 53 \\
Matzunaga (d) & 403 & 196 & 599 & 11 & 28 \\
Hadjistilianou (e) & 227 & 160 & 387 & 83 & 32 \\
Tot. & 1979 & 1605 & & $(24 \%)$ & 261 & $(76 \%)$ \\
& & & & 344 & \\
\hline
\end{tabular}

$\mathrm{URb}=$ Unilateral retinoblastoma; BRb = Bilateral retinoblastoma; Fam.U = Familial unilateral (retinoblastoma); Fam.B = Familial bilateral (retinoblastoma). (a) J. Paediatr. Ophthamol. \& Strabismus, 1985, (b) Ophthalm. Genet., 1996, (c) Br. J. Ophthalmol., 1988, (d) Hum. Genet., 1990, (e) Eur. J. Cancer, 2007.

this assumption, we have selected, from our series, a group of seven patients who, being affected by bilateral (four cases) or early unilateral retinoblastoma (three cases), had to carry, according to the currently accepted views, a new germline mutation and hence to be the 'founders' of a new series of hereditary retinoblastoma, with a predictable $50 \%$ of affected offspring. These seven patients globally generated nine children of which only one developed a unilateral retinoblastoma (the child of a unilaterally affected patient).

\section{Discussion}

It has been proposed by Knudson, that retinoblastoma is 'caused' by two sequential mutations affecting the RB1 gene (16). This is a rather outdated view of cancer aetiology which does not take into account a large amount of heavy arguments against it, as well as an extraordinary number of new acquisitions.

Genomic instability, ${ }^{39}$ microsatellite instability, ${ }^{40}$ and defects of the DNA mismatch repair system, ${ }^{41}$ as well as alterations of DNA methylation ${ }^{42-46}$ and hystone acethylation/ deacethylation, ${ }^{47-52}$ not only have been found to be involved in the genesis of cancer, but also and more importantly, have largely contributed to the view of cancer as an epigenetic ${ }^{53,54}$ rather than a genetic disease. ${ }^{55}$ As more recently reported, ${ }^{56}$ cancer appears to begin with epigenetic alterations in stem cells, thus implying that epigenetic (or non mutational) loss of gene expression comes more commonly before any mutations in cancer. ${ }^{57,58}$
Also, Duesberg and colleagues ${ }^{59-66}$ have heavily argued against the somatic mutation theory by definitely demonstrating that none of the predictions made by that theory is fulfilled by the evidence, ${ }^{67}$ thus excluding any possible involvement of somatic mutation, and finally demonstrating and highlighting the fundamental role of aneuploidy in the genesis and progression of cancer. ${ }^{68-70}$

Aneuploidy is a common feature in the majority of solid human cancers, and several tumour cell lines show chromosome instability (CIN). This leads to a condition in which the tumour phenotype is the result of the altered dosage of thousands of structural and regulator genes. It is currently assumed that aneuploidy drives carcinogenesis through mutations in specific genes whose altered function causes chromosome instability. ${ }^{71}$

A remarkable feature of retinoblastoma, at this regard, is that loss or inactivation of $\mathrm{Rb}$ protein $(\mathrm{pRb})$ has been associated to aneuploidy and centrosome amplification in human cells, thus underlying the role of this protein in the processes that regulate both chromosomal stability and centrosome homeostasis. Inactivation of $\mathrm{pRb}$ promotes aneuploidy, ${ }^{72}$ probably by uncoupling cell cycle progression from mitotic and centrosome control. ${ }^{73}$ Correct duplication of centrosomes is very important for mitotic spindle organisation and equal chromosome distribution to daughter cells. Centrosome duplication is coordinated with DNA replication through a pathway that requires $\mathrm{pRb}$. Phosphorylation of $\mathrm{pRb}$, releases E2F and leads to CDK2 activation which, through the association with cyclins $\mathrm{E} / \mathrm{A}$, is necessary for centrosomes 
duplication. An alteration of this pathway causes centrosome amplification that in turn increases the frequency of aberrant mitoses (multipolar spindles) and chromosome segregation errors (aneuploidy). ${ }^{74-76}$

As it has been recently showed, the acute $\mathrm{pRb}$ loss induces centrosome amplification and aneuploidy in murine primary fibroblast, thus suggesting a direct link between pRb status, centrosome amplification and chromosomal instability. ${ }^{77}$

Similarly, human papillomavirus type 16 (HPV-16) E7 oncoprotein rapidly induces aberrant centrosome and centriole duplication and aneuploidy ${ }^{78}$ in human cells. Moreover, upon release from mitotic block, normal human pRb-deficient fibroblasts generate aneuploid cells with supernumerary centrosomes by expressing the HPV16-E7 protein; these cells acquire the capability to grow in an anchorage-independent manner as tumour cells do, thus indicating that aneuploidy is an initial mutational step in cell transformation. Interestingly, HPV-DNA has been found in some cases of retinoblastoma, thus confirming a possible role of HPV viral proteins $\mathrm{E} 6$ and $\mathrm{E} 7^{79}$ in the genesis of this cancer.

From the above evidences it seems reasonable to conclude that $\mathrm{pRb}$ dysfunctions could drive aneuploidy and then cancer following several alternative pathways not necessarily encompassing gene mutation. Unfortunately, in spite of such an amount of evidence against the somatic mutation theory and in favour of epigenetic/CIN causation in cancer, retinoblastoma has remained, since 1971, probably the only tumour, in the entire constellation of human cancer, to be blamed upon only two mutations affecting one and a single gene.

But even if one would ignore the above advances in the understanding of cancer aetiology and pathogenesis, the clinical and epidemiological evidences supplied herein, clearly illustrate the flaws of the 'two hit' theory and its related predictions.

As it has been shown, the prediction according to which there must be a difference in the age of incidence of unilateral and bilateral retinoblastoma is essentially based on the inappropriate, incorrect, and artful use of a statistical measurement, such as the 'mean', applied to the distribution of the age at diagnosis for retinoblastoma.

Albert Einstein once said: 'If the facts don't fit the theory, change the facts!' and the impression here is that, on this specific aspect, facts have been changed to a large extent, to fit the theory.

It is clear, looking at the age distribution of retinoblastoma in Fig. 2, that, while the calculation of the 'mean' can be applied to the bilateral cases, its application to the unilateral ones, would lead to biased results. In fact, it is a well known and consolidated opinion, among statisticians, that the mean is a measure exceedingly sensitive to the extreme values, and as such much less reliable than the median in representing highly skewed distributions, ${ }^{80}$ such as the one reported in the diagram for unilateral retinoblastoma. It is not by chance that, when applying the calculation of the median age at diagnosis to our unilateral cases, we found the value of 16 months which is very close and not significantly different from the reported 15 months for the mean age at diagnosis of bilateral retinoblastoma.

It can be concluded that there are no differences in the distributions of the age at diagnosis between unilateral and bilateral retinoblastoma, and that, as a consequence, the differences in the timing of cellular/genetic events, as predicted by the theory, in fact do not exist. This evidence is confirmed by the cumulative analysis of different series reported in Table 1 concerning the percentage of both unilateral and bilateral retinoblastoma diagnosed within the first 2 years of life.

The other prediction made by the 'two hit' theory is that the great majority (more than $90 \%$ ) of all hereditary (familial + new germline) retinoblastoma, must have both eyes involved (bilateral phenotype). As a consequence and complement of this prediction, it should be argued that within the familial retinoblastoma, i.e. the hereditary group 'par excellence', the bilateral phenotype should predominate while the unilateral one must be exceedingly rare, accounting for much less than the predicted $10 \%$ within the larger population of inheritable (familial + new germline) retinoblastoma. This is clearly not the case when considering the analysis of different series reported in Table 2, showing that, on a group of 343 familial retinoblastoma, belonging to a series of 3581 cases, 84 , i.e.: $24 \%$, were unilaterally affected; a figure more than twofold higher than the predicted $10 \%$ within the hereditary (familial + new germline) cases and almost fourfold higher than the predicted $6 \%$ within the general retinoblastoma population.

The 'founder' effect of the 'new germline' retinoblastoma, is another prediction of the 'two hit' theory that deserves further consideration. Although limited to a restricted number of patients, our series of seven 'new germline' retinoblastoma, with only one child affected by unilateral disease, on an offspring of nine children, represents a strong argument against the prediction that $50 \%$ of the offspring of 'new germline' retinoblastoma must be affected as a result of the transmission of the disease from one of the parents.

Further consideration deserves, to conclude, the definition of 'sporadic' as related to retinoblastoma and the consequences of the 'two hit theory'. A 'sporadic' disease is, by definition, a disease occurring upon occasion or in a scattered, isolated or seemingly random way. ${ }^{81}$ According to this definition, if one excludes the familial cases, about $90 \%$ of retinoblastoma is 'sporadic' at diagnosis. However, with the creation of the 'perspective' new germline group of patients, the majority of which carry the bilateral disease phenotype, the 'true' sporadic retinoblastoma group has been reduced to about $60 \%$ essentially, but not exclusively, made of unilaterally affected individuals, and the adjective 'sporadic' has finally been used to unequivocally designate the non heritable form of the disease. Given all of the above, one could reasonably distinguish between two different 'pathogenetic' groups; the heritable (about 40\%) and the non heritable (about 60\%) retinoblastoma, and assume that the underlying causes and biological processes operating within the two groups are different and distinct. Unfortunately, the 'unifying' two hit theory has been the source of major confusion on this topic, since it established (and no evidence against it has been 'officially' admitted so far within the scientific literature) that both the sporadic (non heritable) and the heritable disease depend on one and the same process, i.e.: the loss or inactivation of the RB1 gene. How could this be possible? And also: does this 'unitary' theory explain and fit the clinical and epidemiological reality? 
In a recent paper appeared on the Journal of Human Genetics, Sampieri and Coll., ${ }^{82}$ having found a mutation rate of $37 \%$ in a series of Italian patients with 'hereditary retinoblastoma', conclude that: 'The mutation rate reported in the study is quite similar to that found by other groups using the same methodological approach' and that, given the disappointing results of this investigation, '... Other phenomena, such as epigenetic alterations or a possible inactivation of RB1 through mutation of non-coding sequences, may also be invoked to explain the cause of disease in the remainder of the patients...'.

We have already exposed and documented the reasons why the whole story of the role of the RB1 gene in retinoblastoma is scarcely credible; but, assuming that, according to the theory, both hereditary and non hereditary retinoblastoma depend on mutations affecting one and the same gene, is nothing less than absurd and in striking contrast with the clinical and epidemiological evidences; among others, the fact that the incidence of sporadic (unilateral) retinoblastoma is not equally distributed throughout the world and is higher in less industrialized countries and in less affluent populations relative to other malignancies of early childhood. In particular, non-heritable (sporadic) retinoblastoma has a higher incidence among less affluent populations, suggesting an association with poor living conditions and maybe an infectious aetiology. This variation in incidence may be due to differential exposure to infections or other environmental factors in utero. ${ }^{83}$

\section{Conclusion}

The last 35 years of research in the field of retinoblastoma have been dominated by the 'two hit' theory ${ }^{16}$ and during this period, researchers worldwide have not only chosen to avoid to look at any alternative explanation about its genesis, but have also overlooked a few but substantial discrepancies between the most widely accepted genetic theory and the clinical/epidemiological evidence related to retinoblastoma. It is not by chance, given this situation, that the most important advances in retinoblastoma, have been realised in the field of the clinical diagnosis and treatment, ${ }^{84}$ with no substantial contribution of the genetic investigations and speculations. ${ }^{85,86}$ There might be several explanations for this curious phenomenon, including the interests of scientific/academic lobbies, and those of the major drug companies who presently are the main funding resource of genetic research, worldwide, with the consequent hunt for grants in search of the genetic causes of cancer. Whatever the explanation one would adopt, we believe we should 'go back' to the patients and their sufferings, to recover our dignity of physicians and remember that searching for the causes of diseases in general and cancer in particular, is not a business but the main road leading to the sole and higher scope of our profession, which is the cure of the sick.

\section{Conflict of interest statement}

None declared.

\section{R E F E R E N C E S}

1. Shields CL, Meadows AT, Leahey AM, Shields JA. Continuing challenges in the management of retinoblastoma with chemotherapy. Retina 2004;24(6):849-62.

2. http://www.geneclinics.org/profiles/retinoblastoma/ details.html.

3. http://www.infobiogen.fr/services/chromcancer/Genes/ RB1ID90.html.

4. http://www.cancerindex.org/geneweb/RB1.htm.

5. Fan BJ, Tam PO, Choy KW, Wang DY, Lam DS, Pang CP. Molecular diagnostics of genetic eye diseases. Clin Biochem 2006;39(3):231-9.

6. Blanquet V, Turleau C, Gross-Morand S, Sénamaud-Beaufort F, Doz F, Besmond C. Spectrum of germline mutations in the RB1 gene: a study of 232 patients with hereditary and non hereditary retinoblastoma. Hum Mol Genet 1995;4:383-8.

7. Richter S, Vandezande $\mathrm{K}$, Chen $\mathrm{N}$, et al. Sensitive and efficient detection of RB1 gene mutations enhances care for families with retinoblastoma. Am J Hum Genet 2003;72(2):253-69.

8. http://www.retinoblastomasolutions.org/testsent.html.

9. Nichols KE, Houseknecht MD, Godmilow, Sensitive L, et al. Multistep clinical molecular screening of 180 unrelated individuals with retinoblastoma detects 36 novel mutations in the RB1 gene. Hum Mutat 2005;6:566-74.

10. http://www.cancerindex.org/geneweb/RB1.htm\#t51.

11. Bellan C, De Falco G, Tosi GM, et al. Missing expression of $\mathrm{pRb} 2 / \mathrm{p} 130$ in human retinoblastomas is associated with reduced apoptosis and lesser differentiation invest. Ophthalmol Vis Sci 2002;43:3602-8.

12. Harada K, Toyooka S, Maitra A, et al. Aberrant promoter methylation and silencing of the RASSF1A gene in pediatric tumors and cell lines. Oncogene 2002;21(27):4345-9.

13. Harada K, Toyooka S, Shivapurkar N, et al. Deregulation of caspase 8 and 10 expression in pediatric tumors and cell lines. Cancer Res 2002;62(20):5897-901.

14. Rathi A, Virmani AK, Harada K, et al. Aberrant methylation of the HIC1 promoter is a frequent event in specific pediatric neoplasms. Clin Cancer Res 2003;9(10 Pt 1):3674-8.

15. Shigematsu H, Suzuki M, Takahashi $T$, et al. Aberrant methylation of HIN-1 (high in normal-1) is a frequent event in many human malignancies. Int J Cancer 2005;113(4):600-4.

16. Knudson AG. Mutation and cancer: statistical study of retinoblastoma. Proc Natl Acad Sci U S A 1971;4:820-3.

17. Knudson AG. Heredity and human cancer. Am J Pathol 1974;1:77-84.

18. Knudson AG. The genetics of childhood cancer. Cancer 1975;3(suppl.):1022-6.

19. Knudson AG. Genetics of human cancer. Genetics 1975;79(Suppl):305-16.

20. Knudson AG. Mutation and childhood cancer: a probabilistic model for the incidence of retinoblastoma. Proc Natl Acad Sci 1975;72(12):5116-20.

21. Knudson AG. Mutation and cancer in man. Cancer 1977;39(4 Suppl): 1882-6.

22. Knudson AG. Model for the incidence of embryonal cancers: application to retinoblastoma. Proc Natl Acad Sci 1978;75(5):2453-7.

23. Knudson AG. Hereditary cancer. JAMA 1979;241(3):279.

24. Knudson AG. Persons at high risk of cancer. N Engl J Med 1979;301(11):606-7.

25. Knudson AG. Genetics and cancer. Am J Med 1980;69(1):1-3.

26. Knudson AG. Hereditary cancer, oncogenes, and antioncogenes. Cancer Res 1985;45(4):1437-43.

27. Knudson AG. Hereditary cancers disclose a class of cancer genes. Cancer 1989;63(10):1888-91. 
28. Knudson AG. Antioncogenes and human cancer. Proceedings of the National Academy of Science 1993;90(23):10914-21.

29. Knudson AG. Hereditary cancers: from discovery to intervention. J Natl Cancer Inst Monogr 1995;17:5-7.

30. Knudson AG. Hereditary cancer: two hits revisited. J Cancer Res Clin Oncol 1996;122(3):135-40.

31. Knudson AG. Cancer genetics. Am J Med Genet 2002;111(1):96-102.

32. Knudson AG. Cancer genetics through a personal retrospectroscope. Genes Chromosomes Cancer 2003;38(4):288-91.

33. Knudson AG. Of sea urchins and worms: development and cancer. Cell Death Differ 2004;11(1):11-2.

34. Knudson AG. A personal sixty-year tour of genetics and medicine. Ann Rev Gen Hum Genet 2005; [Epub ahead of print]; http://www.cancerindex.org/geneweb/ RB1.htm\#t51.

35. Pendergrass TW, Davis S. Incidence of retinoblastoma in the United States. Arch. Ophthalmol 1980;98(7):1204-10.

36. Tamboli A, Podgor MJ, Horn JW. The incidence of retinoblastoma in the United States: 1974 through 1985. Arch Ophthalmol 1990;108(1):128-32.

37. Sanders BM, Draper GJ, Kingston JE. Retinoblastoma in Great Britain 1969-80: Incidence, treatment, and survival. $\mathrm{Br} J$ Ophthalmol 1988;72(8):576-83.

38. Mastrangelo D, Acquaviva A, Di Pisa F, Hadjistilianou T, Frezzotti R. Italian register for retinoblastoma. Pros and cons of a retrospective statistical study. Ophthalmic Paediatr Genet 1991;12(2):73-8.

39. Anderson GR. Genomic instability in cancer. Curr Sci 2001;81(5):501-7.

40. Atkin NB. Microsatellite instability. Cytogenet Cell Genet 2001;92:177-81.

41. Karran P. Human mismatch repair: Defects and predisposition to cancer. Encyclopedia of Life Sciences www.els.net.

42. Baylin SB, Herman JG, Graff JR, Vertino PM, Issa JP. Alterations in DNA methylation: a fundamental aspect of neoplasia. Adv Cancer Res 1998;72:141-96.

43. Esteller M, Corn PG, Baylin SB, Herman JG. A gene hypermethylation profile of human cancer. Cancer Res 2001;61:3225-9.

44. Teitz T, Wei T, Valentine MB, et al. Caspase 8 is deleted or silenced preferentially in childhood neuroblastomas with amplification of MYCN. Nat Med 2000;6:529-35.

45. Deng G, Peng E, Gum J, Terdiman J, Sleisenger M, Kim YS. Methylation of hMLH1 promoter correlates with thegene silencing with a region-specific manner in colorectal cancer. Br J Cancer 2002;86(4):574-9.

46. Plass C, Soloway PD. DNA methylation, imprinting and cancer. Eur J Hum Genet 2002;10(1):6-16.

47. Gray SG, Teh BT. Histone acetylation /deacetylation and cancer: An "open" and "shut" case? Curr Mol Med 2001;1(4):401-29.

48. Johnstone RW. Histone deacetylase inhibitors: novel drugs for the treatment of cancer. Nat Rev Drug Discov 2002;1(4):287-99.

49. Vigushin DM, Coombes RC. Histone deacetylase inhibitors in cancer treatment. Anticancer Drugs 2002;1:1-13.

50. Jenuwein T, Allis CD. Translating the histone code. Science 2001;293:1074-80.

51. Nakayama J, Rice JC, Strhal BD, Allis D, Grewal SIS. Role of histone H3 Lysine 9 methylation in epigenetic control of heterochromatin assembly. Science 2000;292:110-3.

52. Esteller M, Herman JG. Cancer as an epigenetic disease: DNA methylation and chromatin alterations in human tumors. J Pathol 2002;196:1-7.

53. Brown R, Strathdee G. Epigenomics and epigenetic therapy of cancer. Trends Mol Med 2002;8(4):S43-8.
54. Jones PA, Baylin SB. The fundamental role of epigenetic events in cancer. Nat Rev Genet 2002;1:415-28.

55. Greener M. Cancer epigenetics enters the mainstream. The Scientist 2005;19(12):18.

56. Feinberg AP, Ohlsson R, Henikoff S. The epigenetic progenitor origin of human cancer. Nat Rev Genet 2006;7:21-33.

57. http://www.medicalnewstoday.com/ medicalnews.php?newsid $=35548$.

58. Tycko B. epigenetic gene silencing in cancer. J Clin Invest 2000;105(4):401-7.

59. Li R, Sonik A, Rasnik D, Duesberg P. Aneuploidy vs. gene mutation hypothesis of cancer: Recent studies claims mutation but is found to support aneuploidy. Proc Natl Acad Sci 2000;97(7):3236-41.

60. Duesberg P, Li R, Rasnick D. Aneuploidy approaching a perfect score in predicting and preventing cancer. Cell Cycle 2004;3:823-8.

61. Duesberg PH. Are cancers dependent on oncogenes or on aneuploidy? Cancer Genet Cytogent 2003;143:89-91.

62. Fabarius A, Hehlmann R, Duesberg PH. Instability of chromosome structure in cancer cells increases exponentially with degrees of aneuploidy. Cancer Genet Cytogenet 2003;143:59-72.

63. Li R, Rasnick D, Duesberg P. Correspondence re: D Zimonjic et al., Derivation of human tumor cells in vitro without widespread genomic instability. Cancer Res 2001; 61: 8838 8844 Cancer Res 2002; 62: 6345-6348 author reply 6348 - 9.

64. Fabarius A, Willer A, Yerganian G, Hehlmann R, Duesberg P. Specific aneusomies in Chinese hamster cells at different stages of neoplastic transformation, initiated by nitrosomethylurea. Proc Natl Acad Sci 2002;99:6778-83.

65. Duesberg P, Stindl R, Li RH, Hehlmann R, Rasnick D. Aneuploidy versus gene mutation as cause of cancer. Curr Sci 2001;81:490-500.

66. Duesberg P, Li R, Fabarius A, Hehlmann R. The chromosomal basis of cancer. Cellular Oncology 2005;27:293-318.

67. Duesberg P, Li R. Multistep carcinogenesis: a chain reaction of aneuploidizations. Cell Cycle 2003;2:202-10.

68. Duesberg P. Does aneuploidy or mutation start cancer? Science 2004;307(5706):41.

69. Rasnick D, Duesberg PH. How aneuploidy affects metabolic control and causes cancer. Biochem J 1999;340:621-30.

70. Duesberg P, Li R, Rasnick D, et al. Aneuploidy precedes, and segregates with chemical carcinogenesis. Cancer Genet Cytogenet 2000;119:83-93.

71. Hede K. Which came first? Studies clarify role of aneuploidy in cancer. J Natl Cancer Inst 2005 19; 97(2): 87- 89.

72. Lentini L, Pipitone L, Di Leonardo A. Functional inactivation of pRB results in aneuploid mammalian cells after release from a mitotic block. Neoplasia 2002;4(5):380-7.

73. Hernando E, Nahle Z, Juan G, et al. Rb inactivation promotes genomic instability by uncoupling cell cycle progression from mitotic control. Nature 2004;430(7001):797-802.

74. Matsumoto Y, Hayashi K. Cyclin-dependent kinase 2 (Cdk2) is required for centrosome duplication in mammalian cells. Curr Biol 1999;8:429-32.

75. Meraldi P, Lukas J, Fry AM, Bartek J, Nigg EA. Centrosome duplication in mammalian somatic cells requires E2F and Cdk2-cyclin A. Nat Cell Biol 1999;2:88-93.

76. Doxsey S, Zimmerman W, Mikule K. Centrosome control of the cell cycle. Trends Cell Biol 2005;6:303-11. Review.

77. Iovino F, Lentini L, Amato A, Di Leonardo A. RB acute loss induces centrosome amplification and aneuploidy in murine primary fibroblasts. Mol Cancer 2006;5:38.

78. Duensing S, Duensing A, Lee DC, et al. Cyclin-dependent kinase inhibitor indirubin-3'-oxime selectively inhibits human papillomavirus type 16 E7-induced numerical centrosome anomalies. Oncogene 2004;23(50):8206-15. 
79. Orjuela M, Castaneda VP, Ridaura C, et al. Presence of human papilloma virus in tumor tissue from children with retinoblastoma: An alternative mechanism for tumor development. Clin Cancer Res 2000;6:4010-6.

80. http://www.ruf.rice.edu/ lane/stat_sim/descriptive/ index.html.

81. http://www.medterms.com/script/main/ art.asp? articlekey=9723.

82. Sampieri K, Hadjistilianou T, Mari F, et al. Mutational screening of the RB1 gene in Italian patients with retinoblastoma reveals 11 novel mutations. J Hum Genet 2006;51(3):209-16.
83. Stiller C, Parkin D. Geographic and ethnic variations in the incidence of childhood cancer. Br Med Bull 1996;52:682-703.

84. Shields CL, Mashayekhi A, Cater J, Shelil A, Meadows AT, Shields JA. Chemoreduction for retinoblastoma: analysis of tumor control and risks for recurrence in 457 tumors. Am J Ophthalmol 2004;138(3):329-37.

85. Mastrangelo D, Lore C. "Back stage" view on "hereditary cancer in ophthalmology: the retinoblastoma paradigm. Med Sci Monit 2005;11(6):LE3-4.

86. Mastrangelo D. Predictive gene testing for retinoblastoma: Still far from routine application. Internet J Ophthalmol Vis Sci 2002:1. 